Article

\title{
Estimating Terrain Slope from ICESat-2 Data in Forest Environments
}

\author{
Xiaoxiao Zhu ${ }^{1,2}$, Sheng Nie ${ }^{1, *}$, Cheng Wang ${ }^{1,2,3}$, Xiaohuan $\mathrm{Xi}^{1}{ }^{1}$, Dong Li ${ }^{1}$, Guoyuan Li ${ }^{4}$, \\ Pu Wang ${ }^{1,2}$, Di Cao ${ }^{1,2}$ and Xuebo Yang ${ }^{1,2}$ \\ 1 Key Laboratory of Digital Earth Science, Aerospace Information Research Institute, Chinese Academy \\ of Sciences, Beijing 100094, China; zhuxx@radi.ac.cn (X.Z.); wangcheng@radi.ac.cn (C.W.); \\ xixh@radi.ac.cn (X.X.); lidong@radi.ac.cn (D.L.); wangpu18@mails.ucas.ac.cn (P.W.); caodi@radi.ac.cn (D.C.); \\ yangxb@radi.ac.cn (X.Y.) \\ 2 College of Resources and Environment, University of Chinese Academy of Sciences, Beijing 100049, China \\ 3 College of Tourism and Geographic Sciences, Yunnan Normal University, Kunming 650500, China \\ 4 Land Satellite Remote Sensing Application Center, Ministry of Natural Resources, Beijing 100048, China; \\ ligy@lasac.cn \\ * Correspondence: niesheng@radi.ac.cn; Tel.: +86-108-217-8120
}

Received: 13 September 2020; Accepted: 9 October 2020; Published: 11 October 2020

check for updates

\begin{abstract}
The global digital elevation measurement (DEM) products such as SRTM DEM and GDEM have been widely used for terrain slope retrieval in forests. However, the slope estimation accuracy is generally limited due to the DEMs' low vertical accuracy over complex forest environments. The Ice, Cloud, and land Elevation Satellite-2 (ICESat-2) mission shows excellent potential for slope estimation because of the high elevation accuracy and unique design of beam pairs. This study aimed to explore the possibility of ICESat-2 data for terrain slope retrieval in the United States forests. First, raw ICESat-2 data were processed to obtain accurate ground surfaces. Second, two different methods based on beam pairs were proposed to derive terrain slopes from the ground surfaces. Third, the estimated slopes were validated by airborne LiDAR-derived slopes and compared with SRTM-derived slopes and GDEM-derived slopes. Finally, we further explored the influence of surface topography and ground elevation error on slope estimation from ICESat-2 data. The results show that the ground surface can be accurately extracted from all scenarios of ICESat-2 data, even weak beams in the daytime, which provides the basis for terrain slope retrieval from ICESat-2 beam pairs. The estimated slope has a strong correlation with airborne LiDAR-derived slopes regardless of slope estimation methods, which demonstrates that the ICESat-2 data are appropriate for terrain slope estimation in complex forest environments. Compared with the method based on along- and across-track analysis (method 1), the method based on plane fitting of beam pairs (method 2) has a high estimation accuracy of terrain slopes, which indicates that method 2 is more suitable for slope estimation because it takes full advantage of more ground surface information. Additionally, the results also indicate that ICESat-2 performs much better than SRTM DEMs and GDEMs in estimating terrain slopes. Both ground elevation error and surface topography have a significant impact on terrain slope retrieval from ICESat-2 data, and ground surface extraction should be improved to ensure the accuracy of terrain slope retrieval over extremely complex environments. This study demonstrates for the first time that ICESat-2 has a strong capability in terrain slope retrieval. Additionally, this paper also provides effective solutions to accurately estimate terrain slopes from ICESat-2 data. The ICESat-2 slopes have many potential applications, including the generation of global slope products, the improvement of terrain slopes derived from the existing global DEM products, and the correction of vegetation biophysical parameters retrieved from space-borne LiDAR waveform data.
\end{abstract}

Keywords: space-borne LiDAR; photon-counting LiDAR; ICESat-2; slope estimation; beam pairs 


\section{Introduction}

The accurate retrieval of Earth's surface topography is essential for modeling coastal flooding, quantifying glacier elevation change, monitoring global climate change, mapping forest structure, and estimating global vegetation biomass [1-8]. Although several previous studies have realized the importance of terrain slope retrieval and successfully derived accurate terrain slopes in small areas $[9,10]$, it is still challenging to consecutively and accurately estimate the terrain slopes over large areas.

The development of space-borne remote sensing techniques provides an opportunity for the global measurement of terrain slopes. Both optical stereo-photogrammetry and synthetic aperture radar (SAR) have been adopted to generate global digital elevation models (DEMs) (e.g., the Advanced Spaceborne Thermal Emission and Reflection Radiometer (ASTER) global digital elevation model (GDEM), TerraSAR-X add-on for digital elevation measurement (TanDEM-X) DEM, Shuttle Radar Topography Mission (SRTM) DEM) [2,5,11-14], which can be used to calculate terrain slopes at a global scale. However, the vertical accuracies of these DEM products are generally less than $15 \mathrm{~m} \mathrm{[15-17],}$ which significantly limits their application in the accurate retrieval of terrain slopes. In contrast, space-borne LiDAR can provide effective samplings with nearly a global extent for accurately measuring the elevation of the Earth's surface, making it a promising technology for terrain slope retrieval at a global scale [18-20].

As the first earth observation LiDAR system, the Ice, Cloud, and Land Elevation Satellite (ICESat)/Geoscience Laser Altimeter System (GLAS) has been successfully applied for terrain slope estimation [21-24]. According to previous studies, there are two methods capable of deriving terrain slopes from large-footprint LiDAR waveform data [20,21,25-27]. The first type of method can simultaneously calculate along-track slopes and across-track slopes based on repeated tracks, but they fail to obtain accurate small-scale terrain slopes due to the limitation of sparse footprint distribution. The other kind of method can estimate within-footprint terrain slopes by analyzing the received waveforms [20-22,28]. Specifically, the within-footprint slopes were obtained by examining the relationship between laser characteristics, surface topography, and waveform feature parameters. This kind of method can receive small-scale terrain slopes to some extent; however, the estimation accuracy is generally limited due to the coupling effect of laser-emitted pulses and surface roughness on slope estimation. Additionally, the canopy returns and ground returns are mixed and not easy to distinguish in complex forest environments, which also induces great uncertainty in slope estimation.

The follow-on mission ICESat-2 was launched in September 2018 to measure the Earth's surface characteristics [18,29-33]. Different from ICESat, ICESat-2 offers an opportunity to accurately estimate small-scale terrain slopes due to the unique sensor design of dense along-track sampling and beam pairs $[18,29,34,35]$. Specifically, the along-track distance of GLAS adjacent footprints is approximately $170 \mathrm{~m}$, while that of ICESat- 2 is only $70 \mathrm{~cm}$. The dense sampling of ICESat- 2 can provide more detailed information about along-track terrain slopes. Additionally, in contrast to ICESat, which only emitted a single beam, ICESat-2 carries a photon-counting LiDAR named the Advanced Topographic Laser Altimeter System (ATLAS), which adopted three pairs of beams. Each pair includes a strong beam and a weak beam, and the beam distance within a pair is approximately $90 \mathrm{~m}[18,36,37]$. Due to the design of beam pairs, ICESat-2 can simultaneously provide abundant information for along-track and across-track slope estimation. In fact, a previous study successfully estimated the local slope of the ice sheet using beam pairs of simulated ICESat-2 data [38]. However, their method has not yet been applied to real ICESat-2 data for testing the algorithm availability. Additionally, no research has been conducted to explore the possibility of ICESat-2 data in terrain slope retrieval over complex forest environments. 
In this study, we aimed to propose effective methods to estimate terrain slope from real ICESat-2 data in forest environments. To fulfill this objective, the ICESat-2 data were first processed to obtain accurate ground surfaces. Then, two different methods were proposed to derive the terrain slopes from ICESat-2 beam pairs. Subsequently, the comparisons among ICESat-2 slopes, airborne LiDAR-derived slopes, SRTM-derived slopes, and GDEM-derived slopes were conducted to evaluate our methods' performance. Finally, we investigated the effects of surface topography and ground elevation error on terrain slope retrieval from ICESat-2 data.

\section{Materials}

\subsection{Study Area}

Our study area includes four experimental forest sites: Harvard Forest (HARV), Smithsonian Conservation Biology Institute (SCBI), San Joaquin Experimental Range (SJER), and Soaproot Saddle (SOAP). Two of the experimental sites are located in the western United States, and the other two are located in the eastern United States. The relevant information about the study area, including the site location and ICESat-2 data distribution, is shown in Figure 1. These experimental sites were selected according to the following three criteria: (1) all the data used for slope estimation and validation must be available; (2) these sites covered different topographies ranging from flat to high relief; and (3) the experimental sites encompassed a variety of forest types and coverage.

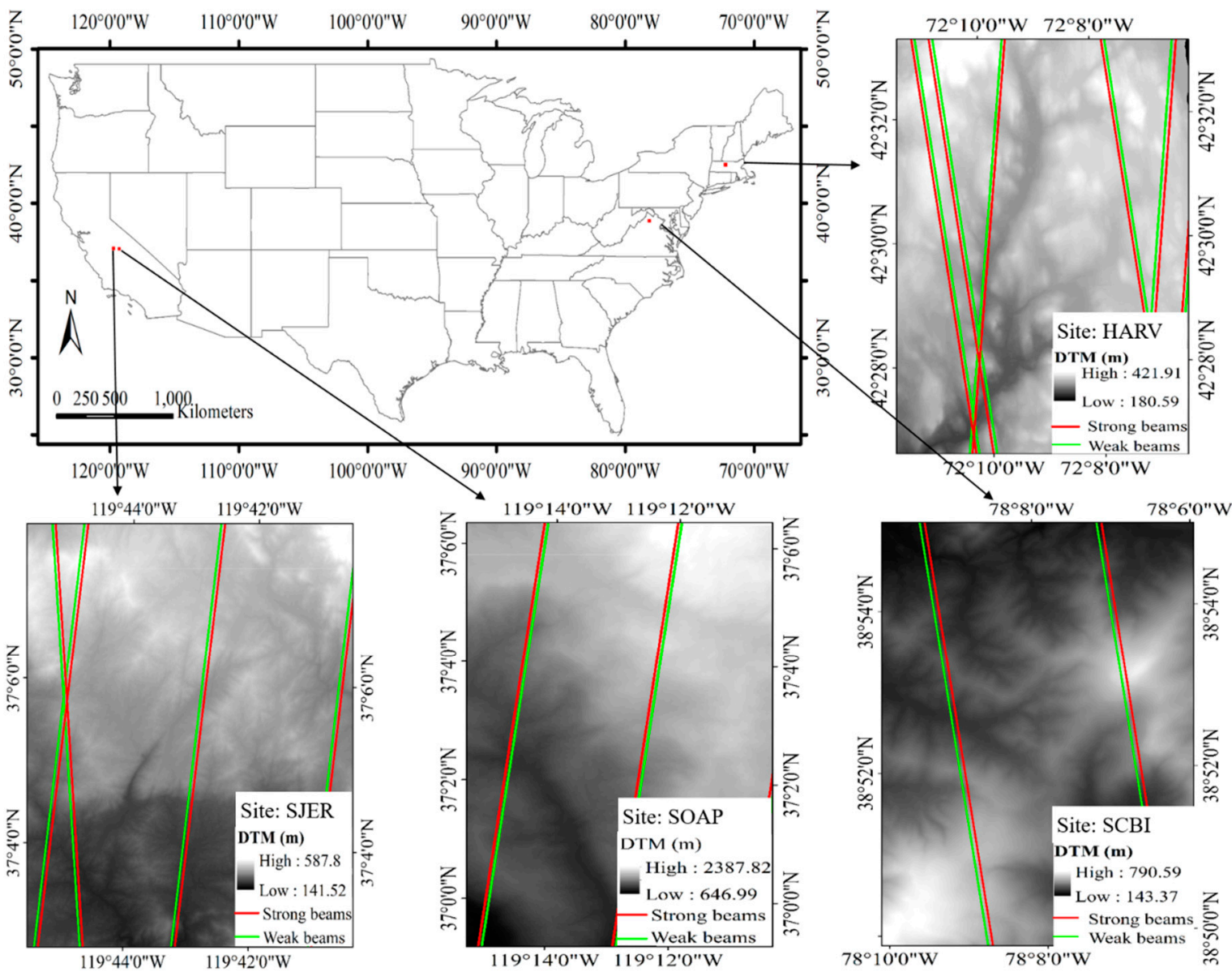

Figure 1. The location of the study area and the distribution of ICESat-2 data. 


\subsection{ICESat-2 Data}

As a follow-on mission of ICESat, ICESat-2 carries a photon-counting LiDAR named ATLAS to measure the elevation of a changing Earth surface. ATLAS employs three-beam pairs to obtain surface elevation profiles, and the pairs are separated by approximately $3.3 \mathrm{~km}$ in the across-track direction. Each pair consists of a strong beam and a weak beam, and their energy ratio is approximately 4:1. The pulse repetition rate of each beam is $10 \mathrm{kHz}$. The ground footprint diameter is $17 \mathrm{~m}$, and the adjacent footprint distance in the along-track direction is $\sim 0.7 \mathrm{~m}$. There are 20 data products (ATL01 to ATL21) for ICESat-2/ATLAS, among which ATL03 is the global geolocated photon product containing the position and elevation information about each photon [18,39]. In this study, we collected ATL03 data from October 2018 to September 2019 on the National Snow and Ice Data Center (NSIDC) website (https://nsidc.org/data/ATL03/versions/3).

\subsection{Airborne LiDAR Data}

Airborne LiDAR data were used to generate reference slopes for accuracy validation and error analysis. The airborne LiDAR data were collected through the National Ecological Observatory Network (NEON) Airborne Observation Platform [40,41]. According to the NEON LiDAR Algorithm Theoretical Basis Document (ATBD), the maximum horizontal and vertical accuracies of NEON LiDAR data are less than $0.4 \mathrm{~m}$ and $0.36 \mathrm{~m}$, respectively, and the elevation datum is referenced to the mean sea level. Given that ICESat-2 data were collected from October 2018 to September 2019, only airborne LiDAR data acquired in 2019 were used in this study to ensure time consistency with ICESat- 2 data.

After collecting airborne LiDAR data, a number of data processing steps, including LiDAR filtering, DTM generation, and reference slope estimation, were taken to generate reference slopes. The details are presented as follows:

(1) LiDAR filtering. The ground returns were separated from non-ground returns using a revised progressive triangular irregular network (TIN) densification (PTD) method [42]. Different from the classic PTD method, the revised method builds an improved TIN and changes the original iterative judgment criterions, thus it has an advantage in preserving key ground points and removing non-ground points that belong to low vegetation.

(2) DTM generation. Once ground returns were obtained, a $1 \mathrm{~m}$-resolution digital terrain model (DTM) was generated by interpolating the ground returns into grids.

(3) Reference slope estimation. Reference slopes were calculated based on the DTMs by the plane fitting for accuracy validation.

\subsection{Other Data}

In this study, both ASTER GDEM and SRTM DEM data were adopted to further evaluate our slope estimation methods' performance, and the terrain slopes of ASTER GDEM and SRTM DEM data were calculated by the ArcGIS software [43]. As the terrain slope retrieval in forests over large areas is generally based on GDEM and SRTM DEM, we compared the estimated slopes with GDEM and SRTM DEM derived slopes to demonstrate that the ICESat-2 data is superior to the existing global DEMs for retrieving terrain slopes over complex forest environments.

ASTER GDEM is a product from METI and NASA, available from $83^{\circ} \mathrm{N}$ to $83^{\circ} \mathrm{S}$, with a spatial resolution of $30 \mathrm{~m}$ [44]. In this study, the second version of GDEM (GDEM2) was used to calculate terrain slopes [2,44]. Compared with the first version of GDEM, GDEM2 has been significantly improved by altering the stereo processing algorithm. However, the horizontal and vertical accuracies of GDEM2 are still very low at $\sim 30 \mathrm{~m}$ and $\sim 20 \mathrm{~m}$, respectively.

The 1-arcsecond (30 m) SRTM DEM is the product generated by a collaborative effort of NASA, NGA, DLR, and ASI. In contrast to ASTER GDEM, SRTM DEM only covers $80 \%$ of the Earth's land surface between $60^{\circ} \mathrm{N}$ and $56^{\circ} \mathrm{S}$ latitude $[2,45,46]$. In this study, we downloaded the third 
version of the SRTM DEM from the United States Geological Survey's EarthExplorer site (http: //earthexplorer.usgs.gov).

\section{Methodologies}

\subsection{ICESat-2 Data Processing and Ground Surface Extraction}

A list of ICESat-2 data processing steps, including data filtering, noise removal, ground surface extraction, and ground elevation validation, was conducted in this study to obtain accurate and reliable ground surfaces, which are prerequisites for terrain slope estimation. The details are presented as follows.

(1) ICESat-2 data filtering. The aim of ICESat-2 data filtering is to obtain photons with high quality by eliminating the cloud effect. Given that the clouds are far above the land surface, ICESat- 2 data whose elevation values are more than $60 \mathrm{~m}$ above the ASTER DEM were regarded as photons affected by clouds and excluded.

(2) Noise photon removal. In this study, the signal photons were separated from noise photons using the noise removal algorithm proposed by our previous studies [37,47]. This algorithm includes two steps. First, elevation frequency histograms were built to remove visible noise photons. Second, density distribution histograms were built to eliminate the remaining noise photons. In prior to establishing density distribution histograms, the density of each photon should be calculated based on photon number in the elliptical neighborhood. A more detailed description of the noise removal algorithm can be found in Zhu et al. [37,47].

(3) Ground surface extraction. There are four key steps to implement ground surface retrieval according to our previous studies [37,47], including initial ground photon extraction, iterative detection of ground photons, ground photon densification, and ground surface fitting. First, a local elevation frequency histogram was built, and the photon at the lowest elevation peak with the maximum density was regarded as the initial ground photon. Second, the empirical mode decomposition (EMD) algorithm was utilized to eliminate wrong ground photons such as canopy photons and noise photons. Third, the number of accurate ground photons was increased based on progressive densification. Finally, all ground photons and corresponding ground surfaces were retrieved utilizing cubic spline interpolation. A more detailed description of the ground surface extraction algorithm can be found in Zhu et al. [47].

(4) Ground elevation validation. Once the ground surface was obtained, the airborne LiDAR-derived DTM was adopted to assess the accuracy of the ground elevation. Compared with strong beams, fewer signal photons in weak beams may reduce the accuracy of the estimated ground elevation. Additionally, photons acquired in the daytime may also introduce more solar background noises than that in the nighttime. To examine the capability of ICESat-2 data in the ground elevation estimation, the ICESat-2 data in four different scenarios were used for ground elevation estimation and validation: 1) ICESat-2 strong beams collected in the daytime, 2) ICESat-2 weak beams collected in the daytime, 3) ICESat-2 strong beams collected in the nighttime, and 4) ICESat-2 weak beams collected in the nighttime. The validation results will guide the slope estimation of ICESat-2 data.

\subsection{Slope Estimation}

In this study, two methods based on beam pairs were proposed to derive terrain slopes from ground surfaces. One method derives the terrain slopes based on along- and across-track analysis and the other method calculates the terrain slopes by the plane fitting. 


\subsubsection{Slope Estimation Method Based on Along- and Across-Track Analysis}

In the method based on along- and across-track analysis, the terrain slope can be divided into the along-track slope $\varphi_{a}$ and across-track slope $\varphi_{c}$. Only the along-track ground photons are used to calculate the along-track slope $\varphi_{a}$ by linearly fitting the photon elevations, while the retrieval of the across-track slope $\varphi_{c}$ relies on both the strong and weak beams. Once $\varphi_{a}$ and $\varphi_{c}$ are obtained, the terrain slope $\varphi$ can be subsequently calculated using the following Equation.

$$
\varphi=\arctan \left(\sqrt{\tan ^{2}\left(\varphi_{a}\right)+\tan ^{2}\left(\varphi_{c}\right)}\right)
$$

As shown in Figure 2, there are a pair of beams (red for beam A and green for beam B), and photon $p$ is located in beam A. To determine the terrain slope of photon $p$, we should first calculate both the along-track slope $\varphi_{a}(p)$ and across-track slope $\varphi_{c}(p)$ of photon $p$. There are three steps to derive the along-track slope of photon $p$. First, we obtain all the photons that are located in beam A and in the 45-m neighborhood of photon $p$. Second, the elevations of all the obtained photons are linearly fitted by line 1, as shown in Equation (2). Finally, $\varphi_{a}(p)$ is calculated according to Equation (3).

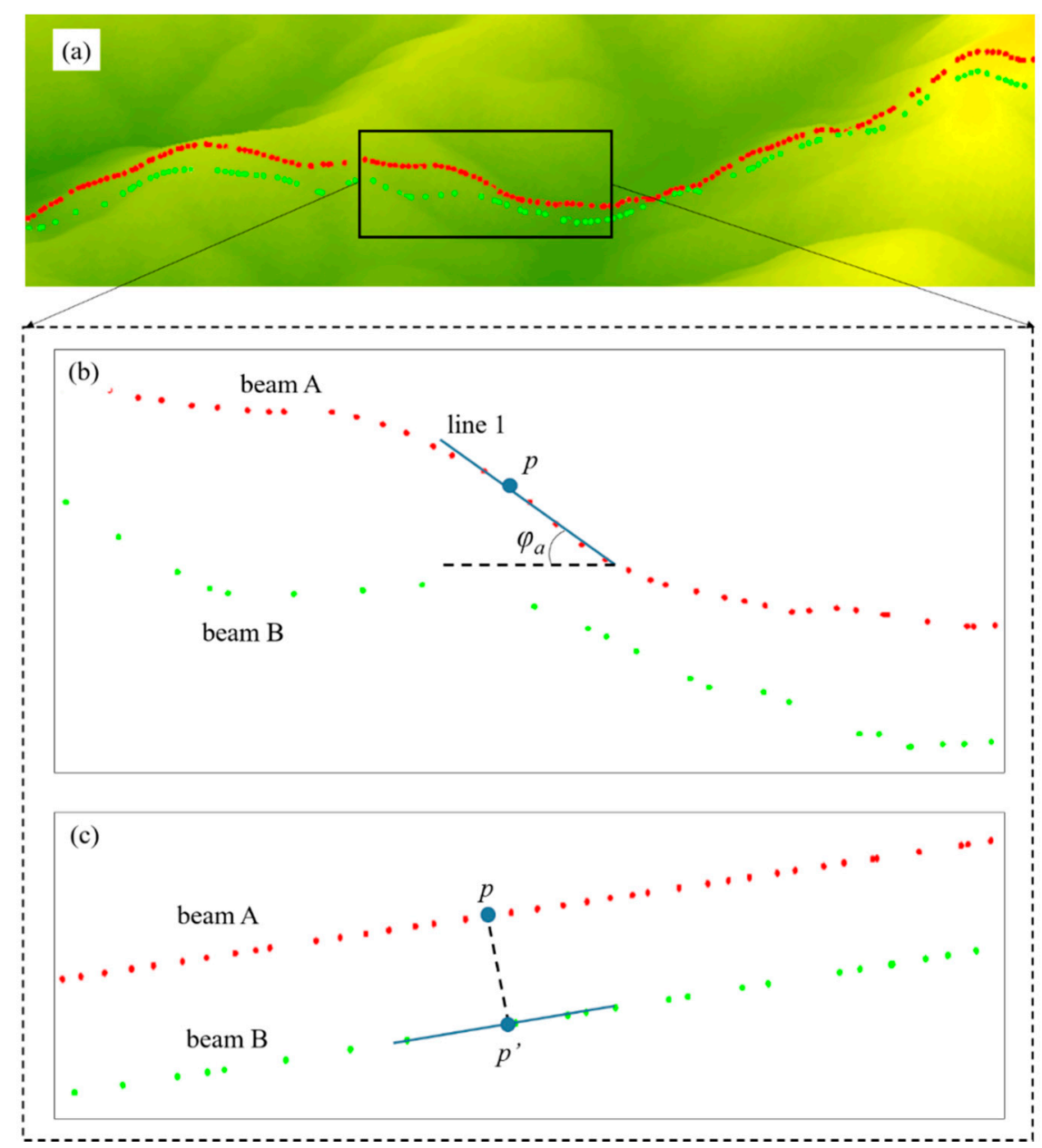

Figure 2. Schematic diagram of slope estimation based on along- and across-track analysis (a) three-dimensional distribution of beam pairs; (b) side view of beam pairs; (c) top view of beam pairs.

To calculate the across-track slope of photon $p$, we should first determine the position of the interpolated photon $p^{\prime}$ in beam B on the basis of the criterion that line $p-p^{\prime}$ is perpendicular to beam A and beam B (see Figure 2c). Then, the elevation of photon $p^{\prime}$ is obtained by inverse distance weighted 
(IDW) interpolation. Once the position and elevation of photon $p^{\prime}$ is determined, the across-track slope can finally be calculated based on the elevations of photons $p$ and $p^{\prime}$, as shown in Equation (4).

In this study, the slope method based on along- and across-track analysis (method 1) can be further divided into three different methods: method1_All, method1_Strong, and method1_Weak. The method1_Strong means that only the terrain slopes of strong beams were calculated by method 1, while the method1_Weak estimates the terrain slopes of weak beams. In contrast to method1_Strong and method1_Weak, method1_All extracted terrain slopes from both the strong and weak beams. For each slope estimation method, we calculated the corresponding slope value at an interval of $\sim 90 \mathrm{~m}$ in the along-track direction given that the distance between beam pairs is approximately $90 \mathrm{~m}$.

$$
\begin{gathered}
z=f(x)=a x+b \\
\varphi_{a}(p)=\arctan (a) \\
\varphi_{c}(p)=\arctan \left[\frac{H\left(p^{\prime}\right)-H(p)}{L}\right]
\end{gathered}
$$

where $z$ is the photon elevation, $x$ is the along-track distance, $a$ and $b$ are the slope coefficient and the intercept, respectively, $H\left(p^{\prime}\right)$ refers to the elevation of interpolated photon $p^{\prime}$, and $H(p)$ refers to the elevation of photon $p$, and $L$ is the distance between beam A and beam B, which is approximately $90 \mathrm{~m}$.

\subsubsection{Slope Estimation Method Based on Plane Fitting of Ground Track Pairs}

This method (named method 2) calculates the terrain slopes from ground track pairs by the plane fitting. It includes four steps. First, the centerline of the ground track pairs is extracted based on the criterion that the distances from the centerline to each ground track are equal. Second, a list of center points are sampled from the centerline by setting the point interval of $90 \mathrm{~m}$, and then we obtain all photons within the grid of $90 \mathrm{~m}$ for each center point. Third, the photon elevations are expressed as a function of the along-track distance and across-track distance and fitted to a plane. Finally, the terrain slope of each center point is calculated based on the fitted plane. As shown in Figure 3, there are a pair of ground beams (red for beam A and green for beam B). Line 2, which is regarded as the centerline, is extracted based on the beam pairs. To estimate the terrain slope of center point $O$, we first obtain all the photons within the dotted rectangle; then a plane (see Equation (5)) is used to fit the photon elevations; the terrain slope of point $O$ is finally calculated based on Equation (6).

$$
\begin{gathered}
z=g(x, y)=a_{x} x+a_{y} y+b \\
\varphi=\arctan \left(\sqrt{a_{x}^{2}+a_{y}^{2}}\right)
\end{gathered}
$$

where $z$ is the photon elevation, $x$ is the along-track distance, $y$ is the across-track distance, $b$ is the intercept, and $a_{x}$ and $a_{y}$ are the slope coefficients.

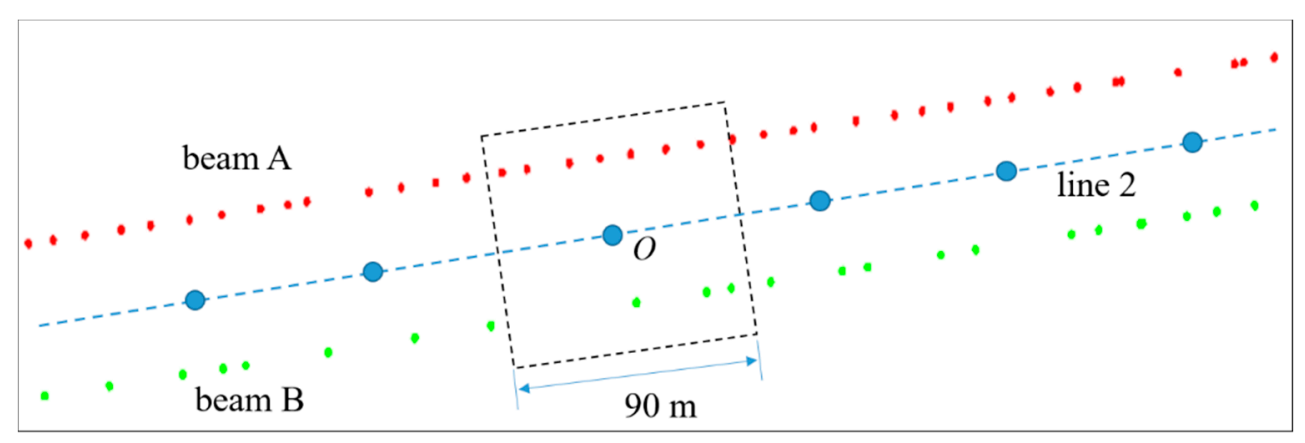

Figure 3. Schematic diagram of slope estimation based on plane fitting of ground track pairs. 


\subsection{Accuracy Validation}

In this study, airborne LiDAR-derived slopes were adopted to check the validity of our slope estimation methods. Four indicators, including the coefficient of determination $\left(\mathrm{R}^{2}\right)$, error bias, standard deviation (SD), and root-mean-square error (RMSE), were used to quantitatively validate the accuracies of terrain slope retrievals from ICESat-2 data. Additionally, the comparison among ICESat-2 slope estimates, GDEM-derived slopes, and SRTM-derived slopes was also conducted further to evaluate the performance of our slope estimation methods.

\subsection{Error Analysis}

Both surface topography and ground elevation error have a significant impact on terrain slope retrieval from ICESat-2 data. Therefore, it is essential to explore the effects of the factors mentioned above on slope estimation. In this study, error analysis was conducted by investigating the changes in terrain slope errors concerning terrain slope and ground elevation error.

\section{Results}

\subsection{Validation of the Ground Elevation Accuracy}

In this study, both qualitative and quantitative assessments were conducted to evaluate the ground surface extraction from ICESat-2 data. The qualitative analysis was made by visual inspection. Figure 4 shows the qualitative results of ground surface retrievals from four different scenarios of ICESat-2 data. From Figure 4, we can see that the ground surfaces can be extracted from all ICESat-2 data, even the weak beams in the daytime.

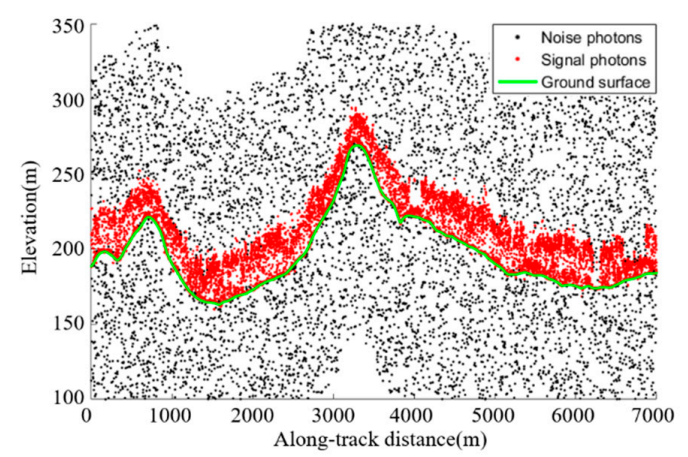

(a)

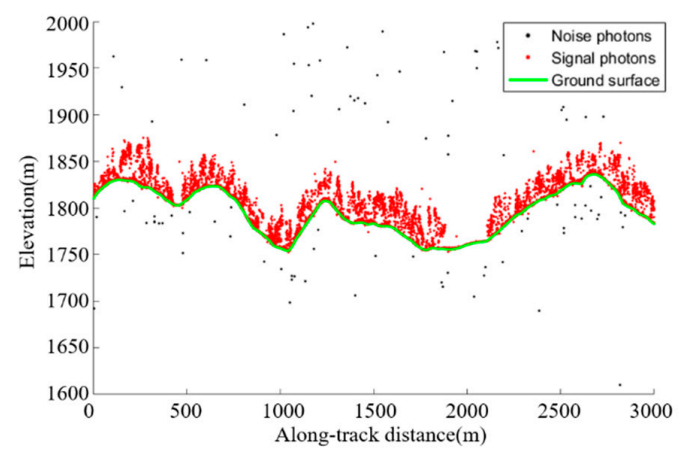

(c)

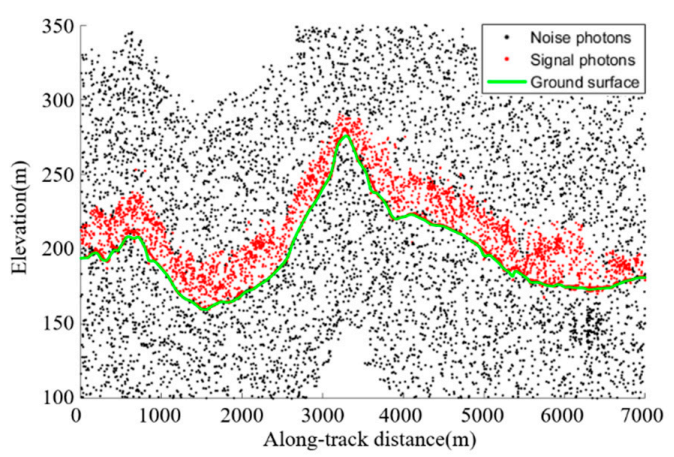

(b)

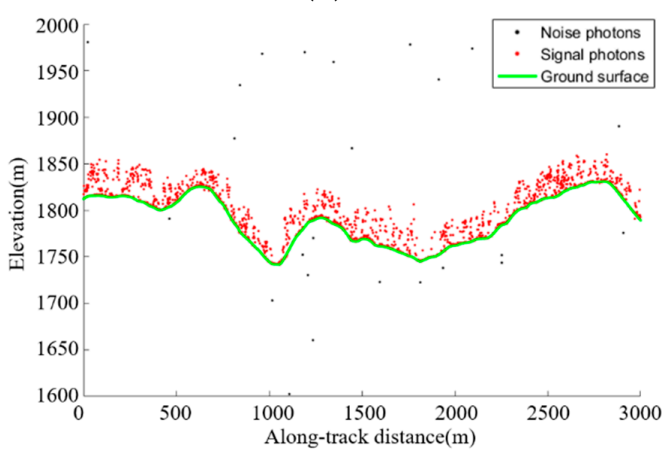

(d)

Figure 4. The qualitative results of ground surface (green line) retrieved from four different scenarios of ICESat-2 data: (a) strong beams of ICESat-2 in the daytime, (b) weak beams of ICESat-2 in the daytime, (c) strong beams of ICESat-2 in the nighttime, and (d) weak beams of ICESat-2 in the nighttime. 
To further evaluate the performance of ICESat-2 data in extracting the ground surface, we validated the accuracy of the ground elevation with airborne LiDAR-derived DTM. The quantitative statistics of ground elevation errors are summarized in Table 1, and Figure 5 shows the frequency histogram of ground elevation errors. According to Table 1 and Figure 5, strong consistency was observed between the estimated ground elevation with the airborne LiDAR-derived DTM, as indicated by high $\mathrm{R}^{2}$ and low RMSE for all scenarios of ICESat- 2 data. Additionally, Table 1 and Figure 5 also indicate that the strong beams have higher estimation accuracy of the ground elevation than that of the weak beams, and ICESat-2 data at night perform much better than those in the daytime for retrieving ground elevation due to higher $\mathrm{R}^{2}$ and lower SD and RMSE.

Table 1. The statistical errors of ground elevation using four different scenarios of ICESat-2 data.

\begin{tabular}{ccccc}
\hline Datasets & $\mathbf{R}^{\mathbf{2}}$ & Bias $(\mathbf{m})$ & SD $(\mathbf{m})$ & RMSE $(\mathbf{m})$ \\
\hline Strong beams in the daytime & 1.000 & -2.563 & 3.112 & 4.031 \\
Weak beams in the daytime & 1.000 & -2.477 & 4.464 & 5.105 \\
Strong beams in the nighttime & 1.000 & -1.388 & 2.037 & 2.465 \\
Weak beams in the nighttime & 1.000 & -1.638 & 3.211 & 3.605 \\
All datasets & 1.000 & -1.816 & 3.056 & 3.555 \\
\hline
\end{tabular}

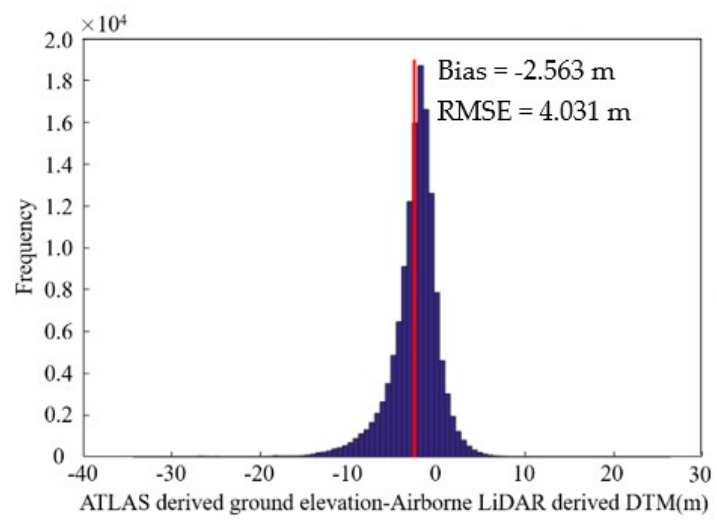

(a)

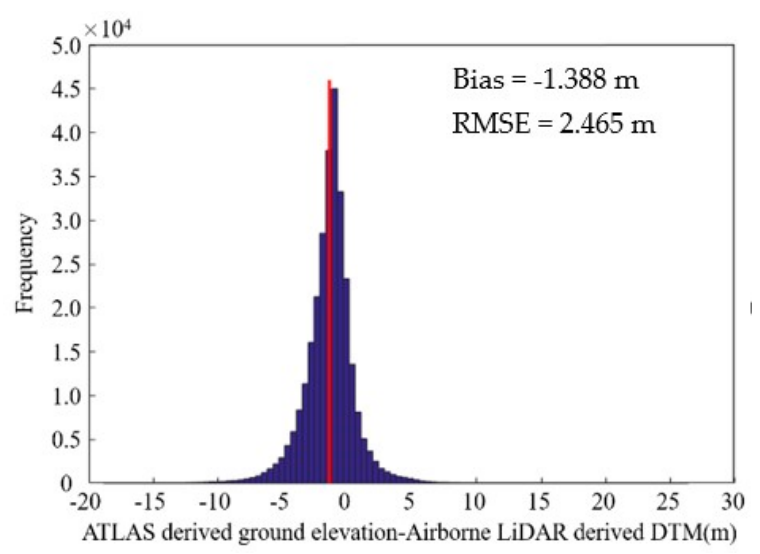

(c)

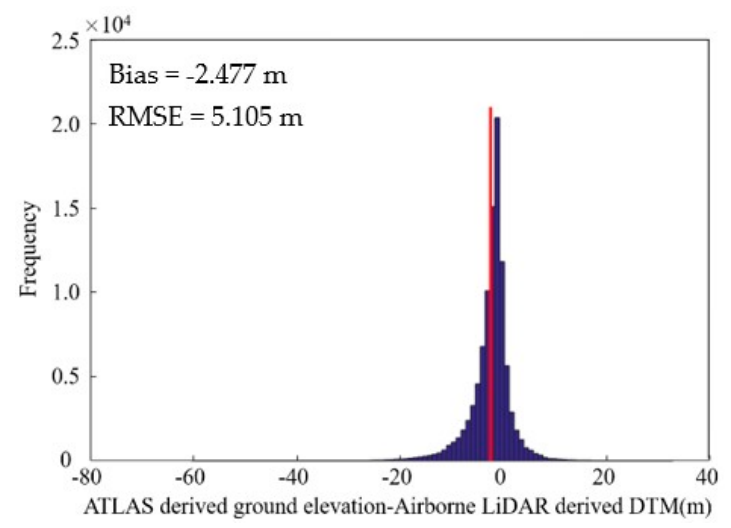

(b)

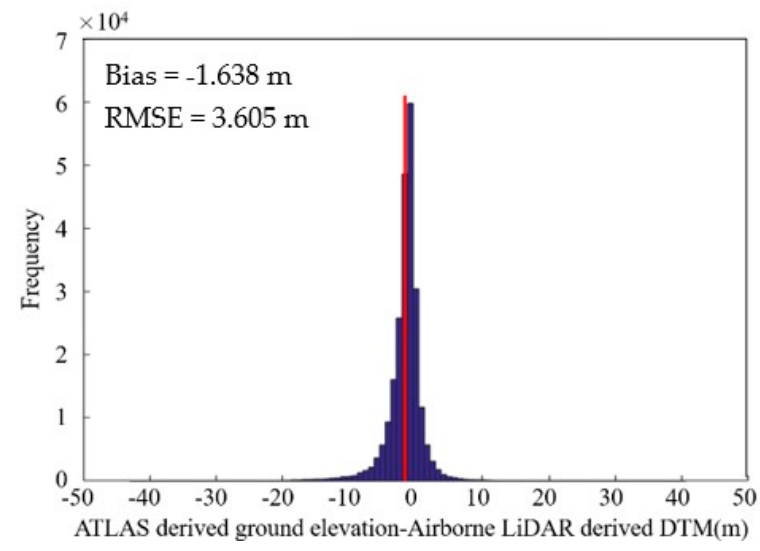

(d)

Figure 5. The frequency histogram of ground elevation errors using four different scenarios of ICESat-2 data (a) strong beams of ICESat-2 in the daytime, (b) weak beams of ICESat-2 in the daytime, (c) strong beams of ICESat-2 in the nighttime, and (d) weak beams of ICESat-2 in the nighttime. 


\subsection{The Assessment of ICESat-2-Derived SLOPES}

To evaluate our methods' performance, we compared the estimated terrain slopes with the airborne LiDAR-derived terrain slopes, and the relevant results are shown in Table 2 and Figure 6. According to Table 2 and Figure 6, a strong positive correlation was observed between the estimated slopes and LiDAR-derived slopes due to the high $\mathrm{R}^{2}$ and low RMSE for all slope estimation methods, and the slope estimation accuracies differ across various experimental sites. Additionally, there is a slight underestimation of ICESat-2-derived slopes compared with LiDAR-derived slopes regardless of estimation methods. Among all methods, method 2 performed best, followed by method1_Strong, and method1_Weak performed worst in terrain slope retrieval as indicated by Table 2 and Figure 6.

Table 2. The statistical slope errors using different methods across various experimental sites.

\begin{tabular}{cccccc}
\hline Sites & Methods & Number & Bias $\left(^{\circ}\right)$ & SD $\left(^{\circ}\right)$ & RMSE $\left(^{\circ}\right)$ \\
\hline \multirow{3}{*}{ HARV } & method1_All & 391 & 0.891 & 2.174 & 2.347 \\
& method1_Strong & 201 & 0.630 & 2.123 & 2.210 \\
& method1_Weak & 190 & 1.168 & 2.199 & 2.485 \\
& method 2 & 201 & 0.805 & 1.332 & 1.553 \\
SCBI & method1_All & 1204 & -0.086 & 2.870 & 2.870 \\
& method1_Strong & 602 & -0.116 & 2.879 & 2.879 \\
& method1_Weak & 602 & -0.056 & 2.863 & 2.862 \\
& method 2 & 602 & -0.270 & 2.108 & 2.124 \\
SJER & method1_All & 1752 & -0.399 & 3.304 & 3.327 \\
& method1_Strong & 876 & -0.558 & 3.146 & 3.193 \\
& method1_Weak & 876 & -0.240 & 3.450 & 3.456 \\
& method 2 & 876 & -0.780 & 2.128 & 2.265 \\
SOAP & method1_All & 1564 & -0.773 & 4.327 & 4.394 \\
& method1_Strong & 782 & -0.617 & 4.201 & 4.243 \\
& method1_Weak & 782 & -0.929 & 4.446 & 4.539 \\
& method 2 & 782 & -0.769 & 2.828 & 2.929 \\
& method1_All & 4911 & -0.339 & 3.528 & 3.543 \\
All & method1_Strong & 2461 & -0.371 & 3.412 & 3.432 \\
& method1_Weak & 2450 & -0.306 & 3.640 & 3.652 \\
& method 2 & 2461 & -0.522 & 2.363 & 2.419 \\
\hline
\end{tabular}

Additionally, we also compared the slope estimation accuracy of ICESat-2 data in the daytime with that of ICESat-2 data in the nighttime, as shown in Table 3. From Table 3, we know that the accuracies of terrain slopes extracted by ICESat-2 data in the daytime are lower than those in the nighttime regardless of slope estimation methods.

Table 3. The statistical slope errors of our methods using different ICESat-2 data.

\begin{tabular}{cccccc}
\hline Data Time & Methods & Number & Bias $\left(^{\circ}\right)$ & SD $\left({ }^{\circ}\right)$ & RMSE $\left(^{\circ}\right)$ \\
\hline \multirow{2}{*}{ Daytime } & method1_All & 1462 & -0.752 & 4.311 & 4.374 \\
& method1_Strong & 731 & -0.582 & 4.198 & 4.236 \\
& method1_Weak & 731 & -0.922 & 4.417 & 4.509 \\
& method 2 & 731 & -0.769 & 2.831 & 2.932 \\
\multirow{2}{*}{ Nighttime } & method1_All & 3449 & -0.163 & 3.121 & 3.125 \\
& method1_Strong & 1730 & -0.282 & 3.016 & 3.028 \\
& method1_Weak & 1719 & -0.043 & 3.220 & 3.220 \\
\hline
\end{tabular}




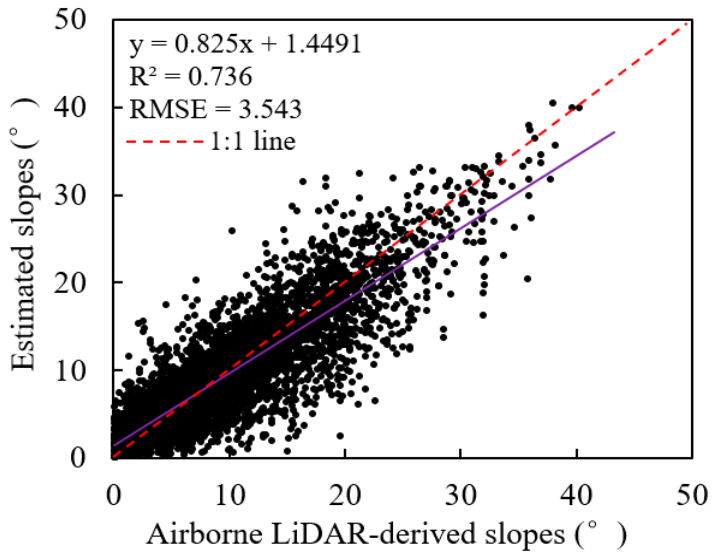

(a)

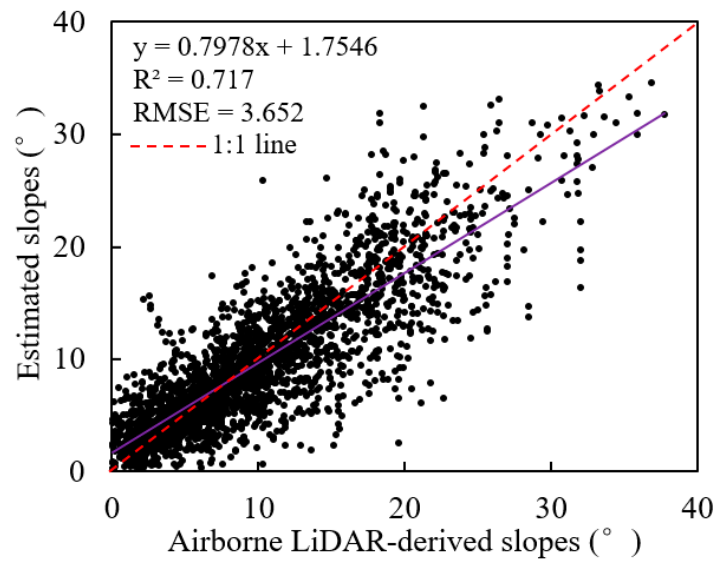

(c)

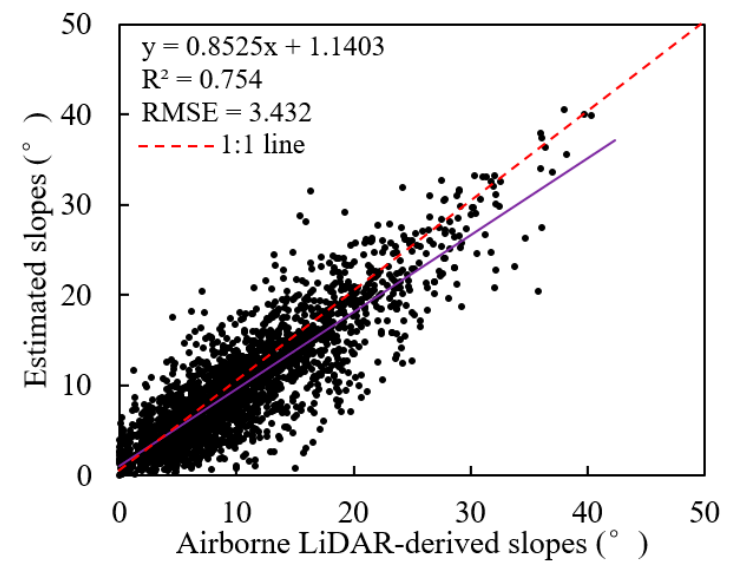

(b)

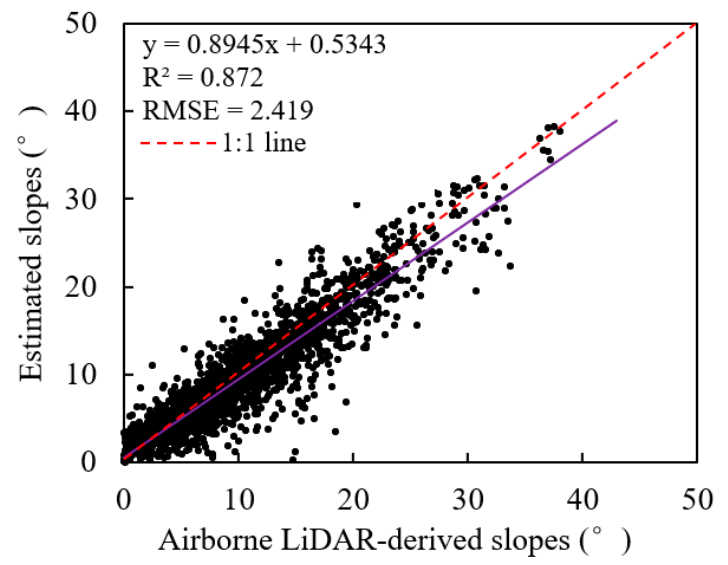

(d)

Figure 6. The scatterplots of airborne LiDAR-derived slopes versus estimated slopes using different methods (a) method1_All, (b) method1_Strong, (c) method1_Weak, and (d) method 2.

To further evaluate the performance of ICESat-2 in estimating terrain slopes, we also compared the estimated slopes with SRTM-derived slopes and GDEM-derived slopes. The relevant results are shown in Table 4 and Figure 7. According to Table 4 and Figure 7, our new proposed methods perform much better than ASTER GDEM and SRTM DEM in estimating terrain slopes due to the higher $\mathrm{R}^{2}$, lower SD, and RMSE.

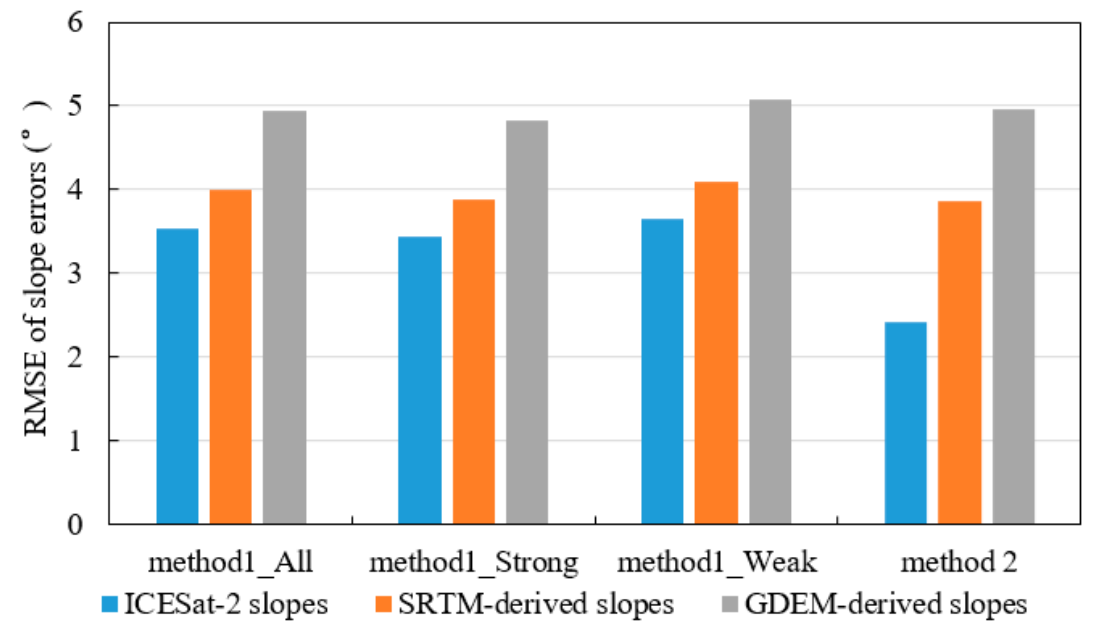

Figure 7. The RMSE of ICESat-2 estimated slopes, SRTM-derived slopes, and GDEM-derived slopes. 
Table 4. The comparison results among ICESat-2 estimated slopes, SRTM-derived slopes, and GDEM-derived slopes.

\begin{tabular}{ccccc}
\hline Methods & Slope Errors & ICESat-2 Slopes & $\begin{array}{c}\text { SRTM-Derived } \\
\text { Slopes }\end{array}$ & $\begin{array}{c}\text { GDEM-Derived } \\
\text { Slopes }\end{array}$ \\
\hline \multirow{3}{*}{ method1_All } & $\mathrm{R}^{2}$ & 0.736 & 0.676 & 0.592 \\
& Bias & -0.339 & -0.928 & 1.125 \\
& SD & 3.528 & 3.883 & 4.822 \\
method1_Strong & RMSE & 3.543 & 3.992 & 4.951 \\
& $\mathrm{R}^{2}$ & 0.754 & 0.692 & 0.607 \\
& Bias & -0.371 & -0.935 & 1.062 \\
& SD & 3.412 & 3.770 & 4.705 \\
method1_Weak & RMSE & 3.432 & 3.884 & 4.822 \\
& $\mathrm{R}^{2}$ & 0.717 & 0.660 & 0.577 \\
& Bias & -0.306 & -0.92 & 1.194 \\
& SD & 3.640 & 3.994 & 4.942 \\
method 2 & RSE & 3.652 & 4.097 & 5.083 \\
& $\mathrm{R}^{2}$ & 0.872 & 0.681 & 0.573 \\
& Bias & -0.522 & -0.868 & 1.064 \\
& SD & 2.363 & 3.766 & 4.837 \\
\hline
\end{tabular}

\subsection{Error Analysis of ICESat-2 Derived Slopes}

\subsubsection{The Effect of Surface Topography on Terrain Slope Retrieval}

To further explore the influence of surface topography on terrain slope estimation from ICESat-2 data, we investigated the relationship between slope errors and terrain slope. In this paper, ICESat-2 data were divided into four groups according to the slope values with intervals of $5^{\circ}$. The statistical slope errors of the different methods for each group are summarized in Table 5 . Additionally, the relationship between the RMSE of slope errors and terrain slope is shown in Figure 8. According to Table 5 and Figure 8, the slope errors show an increasing trend with terrain slope regardless of slope estimation methods. This means that the surface topography has a significant impact on terrain slope retrievals from ICESat-2 data.

Table 5. Statistical errors of different methods, classified by slope.

\begin{tabular}{cccccc}
\hline \multirow{2}{*}{ Methods } & Slope Errors $\left(^{\circ}\right)$ & \multicolumn{4}{c}{ Slope $\mathbf{(}^{\circ}$ ) } \\
\cline { 3 - 6 } & & $\mathbf{0 - 5}$ & $\mathbf{5 - 1 0}$ & $\mathbf{1 0 - 1 5}$ & $\mathbf{1 5}$ \\
\hline \multirow{3}{*}{ method1_All } & Number & 1217 & 1533 & 1097 & 1064 \\
& Bias & 1.208 & -0.076 & -0.768 & -2.043 \\
& SD & 2.340 & 2.842 & 3.451 & 4.621 \\
& RMSE & 2.633 & 2.842 & 3.534 & 5.051 \\
method1_Strong & Number & 573 & 817 & 553 & 518 \\
& Bias & 1.002 & -0.172 & -0.672 & -1.885 \\
& SD & 2.330 & 2.957 & 3.436 & 4.294 \\
& RMSE & 2.535 & 2.960 & 3.498 & 4.685 \\
method1_Weak & Number & 644 & 716 & 544 & 546 \\
& Bias & 1.392 & 0.033 & -0.866 & -2.194 \\
& SD & 2.335 & 2.702 & 3.467 & 4.911 \\
& RMSE & 2.717 & 2.700 & 3.570 & 5.374 \\
method 2 & Number & 617 & 782 & 559 & 503 \\
& Bias & 0.465 & -0.405 & -0.884 & -1.513 \\
& SD & 1.462 & 1.937 & 2.417 & 3.171 \\
& RMSE & 1.533 & 1.977 & 2.572 & 3.511 \\
\hline
\end{tabular}




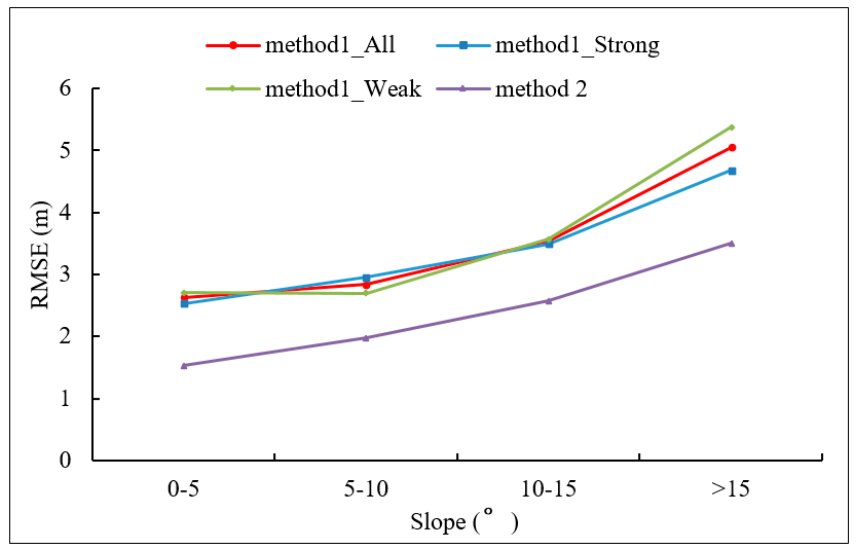

Figure 8. The relationship between the RMSE of slope errors and surface topography.

\subsubsection{The Effect of Ground Elevation Error on Terrain Slope Estimation}

Table 6 shows the statistical errors of different methods for each group classified by ground elevation error. Figure 9 shows the relationship between the RMSE of slope errors and ground elevation error. From Table 6 and Figure 9, we can see that the slope errors increase with an increase in the ground elevation error for all slope estimation methods.

Table 6. Statistical errors of different methods, classified by ground elevation error.

\begin{tabular}{cccccc}
\hline \multirow{2}{*}{ Methods } & Slope Errors $\left(^{\circ}\right)$ & \multicolumn{3}{c}{ RMSE of Ground Elevation Errors (m) } \\
\cline { 3 - 6 } & & $\mathbf{0 - 1}$ & $\mathbf{1 - 2}$ & $\mathbf{2 - 3}$ & $\mathbf{3}$ \\
\hline \multirow{3}{*}{ method1_All } & Number & 490 & 1556 & 1133 & 1732 \\
& Bias & 0.313 & -0.320 & -0.543 & -0.406 \\
& SD & 2.120 & 3.032 & 3.597 & 4.141 \\
& RMSE & 2.141 & 3.048 & 3.637 & 4.160 \\
method1_Strong & Number & 260 & 877 & 628 & 696 \\
& Bias & 0.010 & -0.366 & -0.383 & -0.511 \\
& SD & 2.225 & 3.114 & 3.536 & 3.974 \\
& RMSE & 2.220 & 3.133 & 3.554 & 4.004 \\
method1_Weak & Number & 230 & 679 & 505 & 1036 \\
& Bias & 0.656 & -0.261 & -0.743 & -0.335 \\
& SD & 1.943 & 2.925 & 3.665 & 4.251 \\
& RMSE & 2.047 & 2.935 & 3.736 & 4.262 \\
& Number & 286 & 664 & 462 & 801 \\
method 2 & Bias & -0.096 & -0.392 & -0.663 & -0.614 \\
& SD & 1.276 & 1.885 & 2.370 & 2.899 \\
& RMSE & 1.278 & 1.924 & 2.459 & 2.962 \\
\hline
\end{tabular}

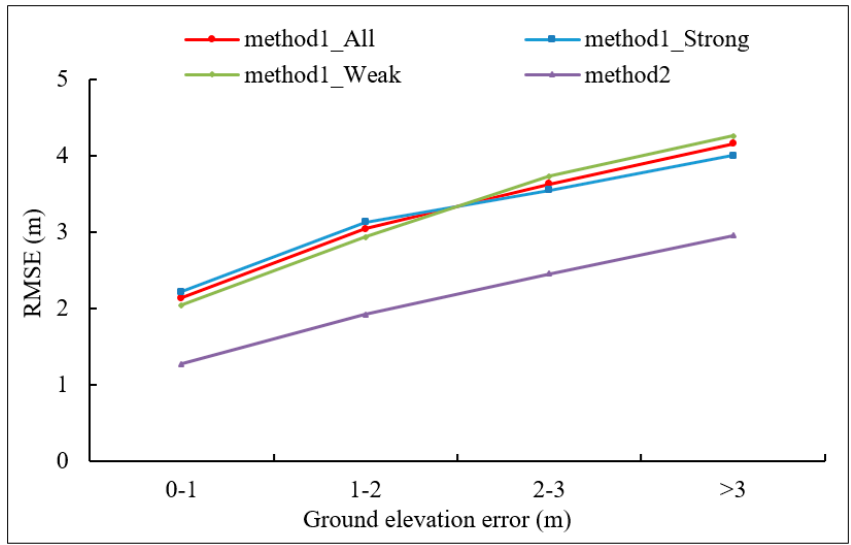

Figure 9. The effect of ground elevation error on terrain slope retrieval. 


\section{Discussion}

\subsection{Ground Surface Retrieval}

Our study demonstrated that both strong and weak beams have a strong capability of accurately extracting ground surfaces, regardless of ICESat-2 data in the daytime or nighttime. This is in agreement with the findings of [48]. In their study, all the ICESat-2 datasets perform well in extracting ground surfaces, which lays the foundation for terrain slope estimation based on beam pairs of ICESat-2 data. Additionally, results also indicated that the strong beams have higher estimation accuracy of the ground elevation than that of the weak beams, and ICESat-2 data at night perform much better than those in the daytime for ground surface retrieval. It is well known that the strong beams with higher energy can obtain denser signal photons than weak beams, resulting in a more detailed and accurate description of the ground surface. Compared with ICESat-2 data in the night, more solar background noises would be induced to the ICESat-2 data in the daytime, thereby significantly affecting the accuracy of ground elevation estimation.

\subsection{The Slope Estimation from ICESat-2 Data}

The ICESat-2 data show strong capability in deriving terrain slopes regardless of estimation methods, which demonstrated that terrain slopes could be accurately estimated from ICESat-2 data even in complex forest environments. Besides, the slope estimation accuracies differ across various experimental sites, which can be explained by the fact that both forest coverage and surface topography may be quite different across various experimental sites.

Compared with LiDAR-derived slopes, a slight underestimation of ICESat-2-derived slopes was observed regardless of estimation methods. This is maybe due to the large footprint size of ICESat- 2 data. In this study, the resolution of LiDAR DTM is $1 \mathrm{~m}$, while the footprint size of ICESat-2 data is large of $17 \mathrm{~m}$. The large size of ICESat-2 data smooths or flattens surface topography, hence resulting in slope underestimation, whereas the smaller DTM cells are more sensitive to surface micro-topography.

Results indicated that terrain slopes could be better extracted from ICESat-2 data in the nighttime compared to ICESat-2 data in the daytime. The reason may be that ICESat-2 data in the daytime introduced abundant solar background noises, which significantly affected the extraction of the ground surface, finally inducing more substantial errors in the terrain slope retrievals. In practical applications, we can only select ICESat-2 nighttime datasets for slope estimation to ensure the terrain slopes' overall accuracies.

Among all the slope estimation methods, method 2 performed best, followed by method1_Strong, and method1_Weak performed worst in terrain slope retrieval. This may be because the slope estimation accuracy can be improved by using more detailed ground surface information. Specifically, method 1 mainly utilizes one ground track to obtain terrain slopes, while method 2 takes full advantage of both strong and weak ground tracks to derive terrain slopes; compared with method1_Weak, method1_Strong can obtain more accurate along-track slopes because strong beams can obtain more effective ground photons to derive along-track slopes.

\subsection{Error Analysis of ICESat-2 Derived Slopes}

In this study, we explored the effect of surface topography on slope estimation using ICESat-2 data and drew a conclusion that the slope errors show a strong correlation with the terrain parameter. This means that the surface topography has a significant impact on terrain slope retrievals from ICESat-2 data. A possible reason is that ground surface extraction is significantly affected by surface topography, as demonstrated by our previous study [37], particularly in forest environments with complex terrain. Given that the slopes were estimated based on ICESat-2-derived ground surfaces, larger uncertainty will be induced with increasing terrain slopes. In future studies, we should focus on ground surface extraction over extreme terrains to improve the accuracy of terrain slope retrieval from ICESat-2 data. Additionally, the results also indicated that the slope estimation from ICESat-2 data is 
highly dependent on ground elevation accuracy. To ensure the reliability of ICESat-2 estimated slopes, we should propose effective methods to improve the estimation accuracy of ground elevation in the case of complex forests or low signal-to-noise ratio (SNR).

\subsection{The Potential Applications of ICESat-2 Sopes}

As demonstrated above, ICESat-2 slopes are accurate and reliable, thus showing great potential in many applications. Below, we presented the potential applications of ICESat- 2 slopes.

(1) The generation of the global terrain slope product.

Although ICESat-2 data can provide accurate terrain slope samplings with global coverage, ICESat-2 slopes are not continuously distributed, limiting their applications in many fields. To generate global terrain slope products, ICESat-2 slopes can be directly interpolated into grids or combined with other continuously distributed remote sensing data using regression analysis.

(2) The improvement of terrain slopes derived from existing global DEM products.

The existing global DEM products, such as GDEM, SRTM DEM, and TanDEM-X DEM, can be used to calculate terrain slopes. However, their estimation accuracies of terrain slopes are generally limited due to the low vertical accuracies of global DEM products. Additionally, these global DEM products generally represent canopy-top surfaces rather than true ground surfaces in forests. Hence, these existing DEM products cannot provide reliable terrain slopes. Given that ICESat-2 can provide effective sampling data with nearly global spatial coverage for accurate retrieval of terrain slopes, ICESat-2 slopes can be adopted as reference slopes to improve the accuracy of terrain slope retrieval from existing global DEM products.

(3) The correction of space-borne LiDAR-derived vegetation biophysical parameters.

The retrieval of vegetation biophysical parameters, including forest height, leaf area index (LAI), and biomass, may be significantly affected by surface topography. To reduce the influence of surface topography on the retrieval of vegetation biophysical parameters from space-borne LiDAR waveform data, terrain slopes should be provided as an input parameter of terrain correction models or auxiliary information. In previous studies, terrain slopes are generally derived from existing global DEM products, even though they are inaccurate. In future studies, the ICESat- 2 slopes can be used to correct the vegetation biophysical parameters that are derived from space-borne LiDAR waveform data, such as GLAS and GEDI.

\subsection{The Innovations and Limitations}

Although a previous study has made an initial attempt to derive the local slope of ice sheet from simulated ICESat-2 data [38], no research has been conducted to explore the potential of real ICESat-2 data in terrain slope retrieval, especially over complex forest environments. Compared with the previous study, our paper has three main innovations:

(1) This paper is the first attempt to derive terrain slopes in forests using ICESat-2 data, providing a new technique for terrain slope retrieval over forest environments.

(2) Two effective methods, which make full use of the unique design of beam pairs, were proposed to accurately estimate terrain slopes from ICESat-2 data. Given ICESat-2 can provide effective samplings at a global extent, the ICESat-2 slopes will lay the foundation for the generation of global terrain slope product and the correction of vegetation biophysical parameters retrieved from space-borne LiDAR waveform data.

(3) This paper not only proposed effective solutions, but also carried out experiments and analysis, illuminating that the proposed methods are capable of obtaining accurate terrain slopes, and perform much better than the existing global DEM products (ASTER GDEM, SRTM DEM) in estimating terrain slopes over forest environments. Additionally, we also quantitatively investigated the effects of surface topography and ground elevation error on terrain slope retrieval from ICESat-2 data.

Although several innovations have been made in this study, there is also a limitation that we fail to accurately extract ground surface form low SNR ICESat-2 data or over extremely complex forest 
environments, significantly affecting the accuracy of terrain slope estimation. In future studies, we should propose effective methods to improve the estimation accuracy of ground elevation in the case of extremely complex forests or low SNR.

\section{Conclusions}

In this paper, we explored the possibility of ICESat-2 data for estimating terrain slopes over complex forest environments. Two methods based on beam pairs were first proposed to derive terrain slopes from ICESat-2 data. Then, the slope estimates were compared with airborne LiDAR-derived slopes, GDEM-derived slopes, and SRTM-derived slopes to evaluate the performance of our methods. Finally, we investigated the effects of surface topography and ground elevation error on terrain slope retrieval from ICESat-2 data. Based on the experimental results, we drew the following conclusions: (1) both strong and weak beams are capable of accurately extracting ground surfaces regardless of using ICESat-2 daytime or nighttime data; (2) the slope estimation accuracies of our methods are high, demonstrating that the ICESat-2 data are suitable for slope estimation in forests; (3) compared with method 1, method 2 can achieve terrain slopes with higher accuracy because it takes full advantage of ground surface information; (4) ICESat-2 data perform better than existing global DEM products in estimating terrain slopes over complex forest environments; and (5) both ground elevation error and surface topography have a significant impact on terrain slope retrieval from ICESat-2 data.

Overall, this paper was the first attempt to derive terrain slopes from ICESat-2 data over complex forest environments, which demonstrated the capability of ICESat-2 data in estimating terrain slope. Additionally, this study provided an effective solution for terrain slope retrieval from ICESat-2 data, which will lay the foundation for the generation of global terrain slope products. As terrain slope estimation is affected by ground elevation error and surface topography, how to propose effective methods for ground surface extraction over extremely complex forest environments or from low-SNR ICESat-2 data has become an emphasis on future research. In addition, our next plan will also focus on the potential applications of ICESat-2 slopes.

Author Contributions: X.Z. and S.N. designed the experiments; X.Z., S.N., C.W., and X.X. processed the data and wrote the paper; D.L. and G.L. analyzed the error factors; P.W., D.C., and X.Y. revised the paper. All authors have read and agreed to the published version of the manuscript.

Funding: This research was funded by the Key Laboratory of Land Satellite Remote Sensing Application Center, Ministry of Natural Resources of the People's Republic of China (KLSMNR-202002), High-Resolution Images Surveying and Mapping Application System of China: Phase II (42-Y30B04-9001-19/21), National Natural Science Foundation of China, granted No. 41901289, 41871264 and 42071405, the Youth Innovation Promotion Association CAS (2019130), and Guangxi Natural Science Fund for Innovation Research Team (2019GXNSFGA245001).

Conflicts of Interest: The authors declare no conflict of interest.

\section{References}

1. Enßle, F.; Heinzel, J.; Koch, B. Accuracy of vegetation height and terrain elevation derived from ICESat/GLAS in forested areas. Int. J. Appl. Earth Obs. 2014, 31, 37-44. [CrossRef]

2. González-Moradas, M.d.R.; Viveen, W. Evaluation of ASTER GDEM2, SRTMv3.0, ALOS AW3D30 and TanDEM-X DEMs for the Peruvian Andes against highly accurate GNSS ground control points and geomorphological-hydrological metrics. Remote Sens. Environ. 2020, 237, 111509.

3. Wang, Z.; Li, Y.; Su, X.; Tao, S.; Feng, X.; Wang, Q.; Xu, X.; Liu, Y.; Michaletz, S.T.; Shrestha, N.; et al. Patterns and ecological determinants of woody plant height in eastern Eurasia and its relation to primary productivity. J. Plant Ecol. 2019, 12, 791-803. [CrossRef]

4. $\quad$ Fricker, G.A.; Synes, N.W.; Serra-Diaz, J.M.; North, M.P.; Davis, F.W.; Franklin, J. More than climate? Predictors of tree canopy height vary with scale in complex terrain, Sierra Nevada, CA (USA). For. Ecol. Manag. 2019, 434, 142-153. [CrossRef]

5. Liu, K.; Song, C.; Ke, L.; Jiang, L.; Pan, Y.; Ma, R. Global open-access DEM performances in Earth's most rugged region High Mountain Asia: A multi-level assessment. Geomorphology 2019, 338, 16-26. [CrossRef] 
6. Muscarella, R.; Kolyaie, S.; Morton, D.C.; Zimmerman, J.K.; Uriarte, M.; Jucker, T. Effects of topography on tropical forest structure depend on climate context. J. Ecol. 2019, 108, 145-159. [CrossRef]

7. Zhang, K.; Gann, D.; Ross, M.; Biswas, H.; Li, Y.; Rhome, J. Comparison of TanDEM-X DEM with LiDAR data for accuracy assessment in a coastal urban area. Remote Sens. 2019, 11, 876. [CrossRef]

8. Eitel, J.U.H.; Höfle, B.; Vierling, L.A.; Abellán, A.; Asner, G.P.; Deems, J.S.; Glennie, C.L.; Joerg, P.C.; LeWinter, A.L.; Magney, T.S.; et al. Beyond 3-D: The new spectrum of lidar applications for earth and ecological sciences. Remote Sens. Environ. 2016, 186, 372-392. [CrossRef]

9. Liu, X.; Hu, H.; Hu, P. Accuracy assessment of LiDAR-derived digital elevation models based on approximation theory. Remote Sens. 2015, 7, 7062-7079. [CrossRef]

10. Polat, N.; Uysal, M. Investigating performance of airborne LiDAR data filtering algorithms for DTM generation. Measurement 2015, 63, 61-68. [CrossRef]

11. Wessel, B.; Huber, M.; Wohlfart, C.; Marschalk, U.; Kosmann, D.; Roth, A. Accuracy assessment of the global TanDEM-X digital elevation model with GPS data. ISPRS J. Photogramm. Remote Sens. 2018, 139, 171-182. [CrossRef]

12. Rizzoli, P.; Martone, M.; Gonzalez, C.; Wecklich, C.; Borla Tridon, D.; Bräutigam, B.; Bachmann, M.; Schulze, D.; Fritz, T.; Huber, M.; et al. Generation and performance assessment of the global TanDEM-X digital elevation model. ISPRS J. Photogramm. Remote Sens. 2017, 132, 119-139. [CrossRef]

13. Carabajal, C.C.; Harding, D.J. ICESat validation of SRTM C-band digital elevation models. Geophys. Res. Lett. 2005, 32, L22S01. [CrossRef]

14. Pham, H.T.; Marshall, L.; Johnson, F.; Sharma, A. A method for combining SRTM DEM and ASTER GDEM2 to improve topography estimation in regions without reference data. Remote Sens Environ. 2018, 210, $229-241$. [CrossRef]

15. Braun, A.; Fotopoulos, G. Assessment of SRTM, ICESat, and survey control monument elevations in Canada. Photogramm. Eng. Remote Sens. 2007, 73, 1333-1342. [CrossRef]

16. Carabajal, C.C.; Harding, D.J. SRTM C-band and ICESat laser altimetry elevation comparisons as a function of tree cover and relief. Photogramm. Eng. Remote Sens. 2006, 72, 287-298. [CrossRef]

17. Zhao, G.; Xue, H.; Ling, F. Assessment of ASTER GDEM performance by comparing with SRTM and ICESat/GLAS data in Central China. In Proceedings of the 18th International Conference on Geoinformatics, Beijing, China, 18-20 June 2010; pp. 1-5.

18. Markus, T.; Neumann, T.; Martino, A.; Abdalati, W.; Brunt, K.; Csatho, B.; Farrell, S.; Fricker, H.; Gardner, A.; Harding, D.; et al. The ice, cloud, and land elevation Satellite-2 (ICESat-2): Science requirements, concept, and implementation. Remote Sens. Environ. 2017, 190, 260-273. [CrossRef]

19. Wang, X.; Cheng, X.; Gong, P.; Huang, H.; Li, Z.; Li, X. Earth science applications of ICESat/GLAS: A review. Int. J. Remote Sens. 2011, 32, 8837-8864. [CrossRef]

20. Nie, S.; Wang, C.; Dong, P.L.; Li, G.C.; Xi, X.H.; Wang, P.; Yang, X.B. A novel model for terrain slope estimation using ICESat/GLAS waveform data. IEEE Trans. Geosci. Remote Sens. 2017, 56, 217-227.

21. $\mathrm{Xu}, \mathrm{L}$. Terrain slope estimation within footprint from ICESat/GLAS waveform: Model and method. J. Appl. Remote Sens. 2012, 6, 063534. [CrossRef]

22. Mahoney, C.; Kljun, N.; Los, S.; Chasmer, L.; Hacker, J.; Hopkinson, C.; North, P.; Rosette, J.; van Gorsel, E. Slope Estimation from ICESat/GLAS. Remote Sens. 2014, 6, 10051-10069. [CrossRef]

23. Li, X.; Xu, K.; Xu, L. Surface slope and roughness measurement using ICESat/GLAS elevation and laser waveform. Meas. Sci. Technol. 2016, 27, 095202. [CrossRef]

24. Nie, S.; Wang, C.; Xi, X.H.; Li, G.Y.; Luo, S.Z.; Yang, X.B.; Wang, P.; Zhu, X.X. Exploring the influence of various factors on slope estimation using large-footprint LiDAR data. IEEE Trans. Geosci. Remote Sens. 2018, 56, 6611-6621. [CrossRef]

25. Yi, D.; Zwally, H.J.; Sun, X. ICESat measurement of Greenland ice sheet surface slope and roughness. Ann. Glaciol. 2005, 42, 83-89. [CrossRef]

26. Howat, I.M.; Smith, B.E.; Joughin, I.; Scambos, T.A. Rates of southeast Greenland ice volume loss from combined ICESat and ASTER observations. Geophys. Res. Lett. 2008, 35. [CrossRef] 
27. Rinne, E.; Shepherd, A.; Palmer, S.; Van Den Broeke, M.; Muir, A.; Ettema, J.; Wingham, D. On the recent elevation changes at the Flade Isblink Ice Cap, Northern Greenland. J. Geophys. Res. 2011, 116, F03024. [CrossRef]

28. Li, X.; Xu, K.; Xu, L. Within-footprint roughness measurements using ICESat/GLAS waveform and LVIS elevation. Meas. Sci. Technol. 2016, 27, 125012. [CrossRef]

29. Neuenschwander, A.; Pitts, K. The ATL08 land and vegetation product for the ICESat-2 Mission. Remote Sens. Environ. 2019, 221, 247-259. [CrossRef]

30. Wise, B.J.A.; Thayer, J.P.; Barton-Grimley, R.A.; Gisler, A.; Anderson, C. Shallow-water bathymetry using ICESat-2 ATLAS and related LIDAR technologies. In Proceedings of the AGU Fall Meeting, San Francisco, CA, USA, 9-13 December 2019.

31. Duncanson, L.; Neuenschwander, A.; Hancock, S.; Thomas, N.; Fatoyinbo, T.; Simard, M.; Silva, C.A.; Armston, J.; Luthcke, S.B.; Hofton, M. Biomass estimation from simulated GEDI, ICESat-2 and NISAR across environmental gradients in Sonoma County, California. Remote Sens. Environ. 2020, 242, 111779. [CrossRef]

32. Kwok, R.; Kacimi, S.; Webster, M.; Markus, T.; Kurtz, N.T. Snow depth on Arctic sea ice from ICESat-2 and CryoSat-2. In Proceedings of the AGU Fall Meeting, San Francisco, CA, USA, 9-13 December 2019.

33. Nie, S.; Wang, C.; Xi, X.H.; Luo, S.Z.; Li, G.Y.; Tian, J.Y.; Wang, H.T. Estimating the vegetation canopy height using micro-pulse photon-counting LiDAR data. Opt. Express 2018, 26, A520-A540. [CrossRef]

34. Neuenschwander, A.L.; Magruder, L.A. Canopy and terrain height retrievals with ICESat-2: A first look. Remote Sens. 2019, 11, 1721. [CrossRef]

35. Kwok, R.; Kacimi, S.; Markus, T.; Kurtz, N.; Studinger, M.; Sonntag, J.; Manizade, S.; Boisvert, L.; Harbeck, J. ICESat-2 surface height and sea ice freeboard assessed with ATM lidar acquisitions from Operation IceBridge. Geophys. Res. Lett. 2019, 46, 11228-11236. [CrossRef]

36. Narine, L.L.; Popescu, S.C.; Malambo, L. Synergy of ICESat-2 and landsat for mapping forest aboveground biomass with deep learning. Remote Sens. 2019, 11, 1503. [CrossRef]

37. Wang, C.; Zhu, X.; Nie, S.; Xi, X.; Li, D.; Zheng, W.; Chen, S. Ground elevation accuracy verification of ICESat-2 data: A case study in Alaska, USA. Opt. Express 2019, 27, 38168-38179. [CrossRef] [PubMed]

38. Brunt, K.M.; Neumann, T.A.; Walsh, K.M.; Markus, T. Determination of local slope on the Greenland Ice Sheet using a multibeam photon-counting Lidar in preparation for the ICESat-2 Mission. IEEE Geosci. Remote Sens. Lett. 2013, 11, 935-939. [CrossRef]

39. Neumann, T.A.; Martino, A.J.; Markus, T.; Bae, S.; Bock, M.R.; Brenner, A.C.; Brunt, K.M.; Cavanaugh, J.; Fernandes, S.T.; Hancock, D.W. The Ice, Cloud, and Land Elevation Satellite-2 mission: A global geolocated photon product derived from the advanced topographic laser altimeter system. Remote Sens. Environ. 2019, 233, 111325. [CrossRef]

40. Carrasco, L.; Giam, X.; Papeş, M.; Sheldon, K. Metrics of lidar-derived 3D vegetation structure reveal contrasting effects of horizontal and vertical forest heterogeneity on bird species richness. Remote Sens. 2019, 11, 743. [CrossRef]

41. Kampe, T.U.; Johnson, B.R.; Kuester, M.; Keller, M. NEON: The first continental-scale ecological observatory with airborne remote sensing of vegetation canopy biochemistry and structure. J. Appl. Remote Sens. 2010, 4, 043510. [CrossRef]

42. Nie, S.; Wang, C.; Dong, P.; Xi, X.; Luo, S.; Qin, H. A revised progressive TIN densification for filtering airborne LiDAR data. Measurement 2017, 104, 70-77. [CrossRef]

43. Burrough, P.A.; McDonell, R.A. Principles of Geographical Information Systems; Oxford University Press: Oxford, UK, 1998; p. 190.

44. Satge, F.; Bonnet, M.P.; Timouk, F.; Calmant, S.; Pillco, R.; Molina, J.; Lavado-Casimiro, W.; Arsen, A.; Cretaux, J.F.; Garnier, J. Accuracy assessment of SRTM v4 and ASTER GDEM v2 over the Altiplano watershed using ICESat/GLAS data. Int. J. Remote Sens. 2015, 36, 465-488. [CrossRef]

45. Cheung, S.; Slatton, K.C.; Cho, H.-C. Fusing landscape accuracy-dependent SRTM elevation data with NGDC and LiDAR data for the Florida coastline. Remote Sens. Lett. 2012, 3, 687-696. [CrossRef]

46. Su, Y.; Guo, Q. A practical method for SRTM DEM correction over vegetated mountain areas. ISPRS J. Photogramm. Remote Sens. 2014, 87, 216-228. [CrossRef] 
47. Zhu, X.; Nie, S.; Wang, C.; Xi, X.; Hu, Z. A ground elevation and vegetation height retrieval algorithm using micro-pulse photon-counting lidar data. Remote Sens. 2018, 10, 1962. [CrossRef]

48. Zhu, X.; Nie, S.; Wang, C.; Xi, X. The performance of ICESat-2's strong and weak beams in estimating ground elevation and forest height. In Proceedings of the IEEE International Geoscience and Remote Sensing Symposium, IGARSS 2020, Virtual Symposium, Waikoloa, HI, USA, 26 September-2 October 2020.

(c)

(C) 2020 by the authors. Licensee MDPI, Basel, Switzerland. This article is an open access article distributed under the terms and conditions of the Creative Commons Attribution (CC BY) license (http://creativecommons.org/licenses/by/4.0/). 